\section{Nuevos avances en el conocimiento de la autofagia en la patología cardíaca}

Kuhn Ch, Menke M, Senger F, Mack C, Dierck F, Hille $\mathrm{S}$, et al. FYCO1 Regulates Cardiomyocyte Autophagy and Prevents Heart Failure Due to Pressure Overload In Vivo. JACC Basic Transl Sci. 2021;6(4):365-80. https://doi.org/10.1016/j.jacbts.2021.01.001.

La insuficiencia cardíaca es un cuadro clínico de etiología múltiple y fisiopatológicamente complejo, aún no del todo conocido. En su evolución, el corazón insuficiente sufre un remodelado miocárdico que se caracteriza por un aumento en el tamaño de los miocitos, modificaciones en la matriz extracelular, junto con alteraciones moleculares que llevan a la disfunción diastólica y sistólica. En los últimos años, se prestó especial atención al estudio de la homeostasis proteica como un mecanismo relevante en la patogénesis de la insuficiencia cardíaca y las miocardiopatías. En este sentido, existen dos mecanismos que participan en la regulación del recambio proteico celular, uno es el sistema ubiquitina-proteosoma, y el otro es el sistema autofágico-lisosomal. La autofagia es un mecanismo intracelular de degradación dependiente de los lisosomas que permite la inclusión de material citosólico, desde proteínas hasta organelas defectuosas o disfuncionales, en vesículas llamadas autofagosomas. Los autofagosomas se fusionan con los lisosomas para el proceso de degradación y reciclado. De esta manera, la autofagia es un importante mecanismo de adaptación de las células a situaciones de estrés. Las alteraciones en los mecanismos normales de control de calidad proteica son una vía común de distintas patologías que culminan en el corazón insuficiente, pero los mecanismos regulatorios de la autofagia en estas condiciones de estrés son poco conocidos.

En este trabajo, Kuhn y cols. realizaron una sólida investigación bioinformática en la que identificaron una variedad de secuencias correspondientes al gen FYCO1. Este se encuentra altamente expresado en el corazón y tiene la capacidad de interactuar directamente con LC3, Rab7 y fosfatidilinositol 3-fosfato, tres mediadores claves en la autofagia. Los autores muestran que el FYCO1 es un potente inductor de la autofagia en el cardiomiocito, que promueve tanto la formación del autofagosoma como el flujo autofágico en el corazón sometido a sobrecarga de presión. Además, la falta de FYCO1 in vivo inhibe la adaptación del corazón a la inanición y al estrés biomecánico por una falta en el incremento del flujo autofágico, lo cual tiene como resultado una disfunción contráctil. Por el contrario, la sobreexpresión cardíaca específica de FYCO1 incrementa el flujo autofágico y mejora la función contráctil en corazones de ratones con sobrecarga de presión por banding aórtico.

La estimulación de la autofagia en niveles adecuados es fundamental para mantener el equilibrio proteico y la actividad de las organelas y, así, el correcto funcionamiento del corazón ante situaciones de estrés. En condiciones patológicas, la autofagia solo se activa por debajo de niveles fisiológicos, como consecuencia de la presencia de mecanismos inhibitorios o de un agotamiento de la maquinaria autofágica. Esto trae como consecuencia la acumulación de organelas disfuncionales y materiales tóxicos celulares que confluyen en un progresivo deterioro del órgano. Si bien en los últimos tiempos distintos trabajos sugieren potenciales intervenciones para incrementar la autofagia cardíaca, el insuficiente conocimiento de esta impide un avance significativo en este campo. Kuhn y cols. proponen una nueva vía de inducción de la autofagia, a través del FYCO1 como componente esencial de la maquinaria autofágica del corazón, lo que constituye una acción favorable que mejora la disfunción cardíaca ante situaciones de estrés. No solo observan que, bajo condiciones patológicas, la disminución del FYCO1 se asocia al deterioro funcional del órgano, sino también, que su sobreexpresión es una vía efectiva para aumentar la autofagia y mejorar el funcionamiento cardíaco. En su conjunto, esto posiciona al FYCO1 como un potencial blanco terapéutico para la insuficiencia cardíaca inducida por sobrecarga de presión. Más estudios son necesarios para confirmar estos hallazgos y dilucidar su participación en otras patologías cardiovasculares. 